\title{
The digital economy in the management of socio- economic relations in the global economy
}

\author{
Fatima Dakhaeva ${ }^{1, *}$, and Raisa Datsaeva ${ }^{2}$ \\ ${ }^{1}$ Chechen State University, 364024 Grozny, Russia \\ ${ }^{2}$ Grozny State Oil Technical University named after Academician M.D. Millionshchikova, \\ 36406 Grozny, Russia
}

\begin{abstract}
The continuing complication of social structures and relations, which are increasingly based on modern digital technologies, causing exponential growth in data flows, brings to the fore the question of the formation of the digital economy. The importance of the ongoing processes made it possible to raise the question of the formation of a new type of economy, where relations with regard to the production, processing, storage, transmission, and use of an increasing amount of data acquire dominant importance. The data become the basis for economic analysis, which examines the patterns of functioning of modern socio-economic systems. According to a number of experts, at present, it is important for an economic agent not to possess any resource, but to have data on this resource and the ability to use it to plan its activities.
\end{abstract}

\section{Introduction}

The digital economy is the backbone of development and affects industries as diverse as banking, retail, transportation, energy, education, healthcare, and many others. Digital technologies such as the Internet of Things (IoT), big data, the use of mobile devices and devices are transforming the ways of social interaction, economic relations, and institutions [1]. New ways of cooperation and coordination of economic agents appear for the joint solution of certain problems (sharing economy).

Although the role of the influence of digital technologies on the transformation of socioeconomic systems is quite obvious, many issues remain poorly understood [2]. Insufficient attention is paid to the development of digital potential in order to achieve the innovative growth of individual firms and industries, the institutional aspects of the digital economy remain without due attention, the problems and prospects of business development in the formation of the digital economy are poorly covered, the place of the digital economy in the general system of modern economic relations. Therefore, the purpose of this work is to consider the main aspects of the development of the digital economy and to formulate judgments about its role in the general system of economic relations.

\footnotetext{
*Corresponding author: dahaevaf@ mail.ru
} 


\section{Methodological aspects of the analysis of the digital economy}

To measure the development of the digital economy by the OECD countries, a system of indicators has been developed that characterizes the following areas: development of the high-tech sector of the economy, its share in manufacturing products and services; investments in research and development, software development, education costs, and additional retraining; development and release of information and communication equipment; creation of jobs in the field of science and high technologies; indicators of cooperation between corporations, venture capital firms, universities and research organizations; international flows of knowledge, international cooperation in the field of science and innovation; mobility of scientists, engineers, students; the dynamics of the spread of the Internet; the share of high-tech products in international trade [3].

The versatility of the impact of increasing data flows on the development of society and the economy made it possible to speak of them as a leading resource for the economic growth of modern society [4]. Experts characterize this situation with changes in economic relations and the formation of the digital economy, pointing out the need to search for new approaches to solving the problems of its development.

In general terms, four criteria for analyzing the digital economy can be distinguished, which are considered to one degree or another by various researchers: a criterion related to the sphere of employment; spatial criterion; technological; and, in fact, economic [5]. In this case, complementary criteria are possible, although often researchers bring to the fore one or another definition that corresponds to their own ideas. However, most definitions are based on the belief that quantitative changes in the field of data processing have led to the emergence of qualitatively new socio-economic relations.

Criterion, related to the sphere of employment: This approach is closely related to the works of D. Bell, C. Leadbeater, P. Drucker [6], which consider the structure of employment and the patterns of observed changes. The transformation of socio-economic relations occurs due to the fact that most of the employed work in the digital sphere of the economy. A decrease in the share of those employed in the production sector and an increase in the service sector are seen as the substitution of informational labor for physical labor. Since the main resource, in this case, is data, a significant increase in the share of labor in the field of data processing can be considered as a transition to a digital economy.

Statistical observations show an increased share of people employed in the service sector (in Western Europe, the USA, Japan, this share reaches $70 \%$ or more), most of whom are in one way or another connected with the activity of processing certain data, and therefore, on this basis, it seems quite convincing to prove the existence of the digital economy [6]. The main problem with this approach is the complexity of the data staff. For example, it can be considered that the basis for the formation of the digital economy was the process of increasing the number of computer technology specialists, employees of telecommunications companies, analysts, whose main task is data processing. However, there is currently no methodology for counting workers in the digital economy. At the same time, there is an equally rapid increase in the number of trade workers, lawyers, etc., with a weak connection to the digital economy, but they all fall into the same category.

Spatial criterion: A number of digital economy concepts are based on the geographic principle [9]. The focus is on data networks that link different places and therefore can influence the shaping of the global economic space. Data networks are an important distinguishing feature of modern society. At the same time, an important point is what aspect related to data transmission networks to consider when studying the digital economy. Will it be a purely technological aspect, i.e. the presence of certain data transmission systems in a certain territory, or it is necessary to analyze other aspects, such as the amount of data transmitted over these networks, the quality of this data, etc. A number of more general 
questions are currently being discussed, for example, what really is a network, how to distinguish between different levels of networks, what amounts of data and their transmission rates determine the transition to the digital economy.

Economic criterion: This approach involves taking into account the growth of economic value in the field of activities for the creation, transmission, processing, storage of data [7]. If in the economic sphere this kind of activity prevails over activities in the field of agriculture and industry, then, therefore, we can talk about the transition to a digital economy. In addition, the data itself in such conditions becomes the object of economic relations. Specialized companies, research organizations provide services for the collection and analysis of data for the purposes of the customer and, accordingly, such data acquire a certain value.

The main problem of this approach is that, for the large statistical material indicating the increasing role of data in economic activity, their true impact on the activities of companies has been studied rather superficially, and the methods for assessing the effectiveness of employees' activities related to data processing and interpretation are not enough. developed [8]. For example, the information and analytical department of a manufacturing enterprise are engaged in information activities, but the question of how to isolate its share in the production of the entire company for statistical purposes remains open.

Technological criterion: The technological concept is based on a variety of technological innovations in the field of information and communication technologies, which have become available to a wide range of users [8]. New technologies are the most visible sign of changing economic systems, and they are often referred to as the driver of economic development.

\section{Results and discussions}

The main idea of such reasoning is that the increased volume of technological innovations in the field of data processing and transmission leads to a reorganization of socio-economic relations since their impacts are quite significant. Many researchers in their works note the importance of the influence of technological innovations. This reasoning is supported by the ability of computer technology to transform the telecommunications industry and combine these technologies, resulting in the development of services such as email, data transfer in the form of text, audio and video files, social networks, instant messengers, etc. The spread of digital technologies gives rise to reasoning about the formation of new socio-economic relations, the digital economy [10].

Certain questions arise when researchers try to measure the level of development of the digital economy, relying only on a technological criterion. When it comes to conducting empirical research, it is quite difficult to track how strongly certain digital technologies are developed (firstly, because there are a lot of them; secondly, each of them has its own impact; thirdly, they are constantly evolving) and to what extent it allows the economy to be considered digital [9]. In their quest to discover a reasonable unit of measure, most technology researchers cannot provide simple and verifiable data. Measurement and the associated complexity of finding the point on the technological scale at which the economy can be considered digital is one of the problems of formulating an acceptable definition of the digital economy. This question is bypassed by many modern researchers of informatization processes, limiting themselves to describing technological innovations in the most general terms, believing that this is enough to describe a new type of economy.

Another question arises related to the dominant role of technological criteria in defining the digital economy. Critics disagree with those who argue that in every era of history, technologies are first invented, and only then they have an impact on socio-economic relations. In such statements, technology is given the most privileged place, it changes the needs of society. This leads to an oversimplification of the processes of social change, the 
separation of socio-economic processes from technological innovations. However, it is obvious that technology is not separated from the social field [8]. On the contrary, they are part of the social. Decisions about research and development reflect social priorities. On the basis of these value judgments, certain technologies are developed. Many researchers in their works have shown how technology reflects the values of society.

If all this is taken into account, then it is quite difficult to consider the technological factor to be decisive in changing socio-economic relations and the formation of the digital economy.

After considering various approaches to the definition of socio-economic relations formed on the basis of digital technologies, it becomes clear that at present, sufficiently precise, detailed provisions on this matter have not been formulated. Most researchers focus on quantitative characteristics and assume that at some point in the achievement of a number of quantitative indicators, the digital economy begins to dominate.

However, quantitative indicators of increased data flows cannot by themselves mean a break from previous systems. Questions arise when the digital economy is defined on the assumption that a qualitative change can be determined by simply counting the circulating data, the people involved in processing it, the amount of hardware, telecommunications equipment, etc. Those. here we are dealing with the assumption that a quantitative increase in data is somehow transformed into a qualitative change in the economic system [10].

Therefore, it becomes obvious that along with the analysis of technological development, it is necessary to talk about the qualitative analysis of increasing data. It must be understood that increasing data flows are not a purely quantitative factor and a subject of statistical measurements. However, when calculating the economic value of certain data, the share of their processing in GDP, the qualitative characteristics of the subject are not taken into account. When all the data circulating in the system is considered as a homogeneous mass and becomes available for quantitative measurement, the qualitative side of the issue remains out of sight. Along with the quantitative measurement of data comes the conviction that more of them means a deep transformation of economic relations [8]. Meanwhile, the question of the quality of the data itself, the methods of their processing, and the adoption of effective management decisions on their basis is perhaps the most significant in the conditions of the formation of the digital economy. It is all the more strange that researchers are trying to solve the quality problem using a quantitative approach. Theorists of the digital economy, having excluded the criterion of the usefulness of certain data for the sake of quantitative measurements of their growth, come to the conclusion that due to the increasing economic weight, the amount of data produced, the economy must undergo profound changes. The ability to quantify data dissemination is useful, but it is definitely not enough [9]. To understand the formation of the digital economy, where the main resource is data, it is necessary to understand their quality. The interpretations of those scientists who ask questions about the meaning and quality of data differ significantly from those who operate with non-semantic and quantitative measurements.

A characteristic feature of the increased data flows is the complexity in their structuring, preparation for use, management [8]. In the conditions of market relations, excessive commercialization leads to information asymmetry of economic agents, depletion of public data flows, an increase in transaction costs in the field of data processing, and other negative factors that are a consequence of the development of the digital economy.

The ability to accumulate and create huge reserves of data, the development of ever faster and more capacious devices, communication networks, cloud storage has led to the fact that the only limitations are not the ability to save and transfer data, but the ability to process, the ability to analyze huge amounts of data.

Digital technologies, in particular the Internet, increase the degree of interaction and creative exchange between product developers, suppliers and end-users, researchers and scientists, and enable continuous collaborative work on the creation and modification of 
goods and services, which includes a wide range of users who participate in the process in such work they can find flaws, mistakes and put forward proposals for further development [10].

Large-scale technological changes, when people, using data and communication technologies, interact to produce innovations, are accompanied by a change in the institutional structure of society. For the implementation of social and innovative development of societies, it is necessary to implement the following conditions [9]:

- firstly, the unification of a significant number of community members for the production and broadcast of new knowledge. Implicit knowledge inaccessible to individual individuals, divorced from social interaction, must be disseminated and multiplied.

- secondly, the creation of an "open access" space for the exchange and dissemination of knowledge. Reducing barriers to interaction, geographic, linguistic, and other obstacles and developing new opportunities, in the form of the emergence of social networks, which are of a general or specialized nature.

With increasing data flows, it becomes possible to move to a new level of management of economic processes. Modern data retrieval systems make it possible to automate the process of making managerial decisions and allow for a more detailed analysis of economic activity. Modern databases represent analyze and forecast economic processes at the macro level, the level of individual regions, industries, and enterprises. Modern digital devices, smartphones, the Internet of Things allow receiving data directly from economic agents. Data from such devices allow you to create digital models of consumers, technological processes, which leads to saving resources, optimizing procurement systems, optimizing the use of finance, etc. [8]

The increased use of digital devices has given rise to the concept of big data. Data streams are constantly growing (their volumes are already reaching terabytes and petabytes), are transmitted in real-time, processed, and used for decision-making. The opportunities created by big data are characterized as unprecedented in the development of science and management. Working with big data is the basis for the development of the digital economy [10]. Big data provides a new quality of analysis for socio-economic data. The development of computing power, cloud data processing technologies will allow the development of modeling and forecasting of socio-economic development.

Macroeconomic, socio-demographic, and technological trends of digital transformation, which form the conditions for the digital transformation of enterprises in Russia, determine the system of external and internal factors that limit the digital transformation of enterprises and ensure the acceleration of digital transformation. Table 1 presents a classification of the key factors constraining and limiting the digital transformation of industrial enterprises [7].

The human factor, lack of knowledge, outdated equipment, technologies, and IT systems, customer habits are the main obstacles to the digital transformation of domestic enterprises. The influence of negative factors can be leveled by the activation and strengthening of the impact of factors that contribute to the digital transformation of enterprises and create conditions for accelerating digitalization processes. 
Table 1. Classification of key factors constraining and limiting the digital transformation of industrial enterprises.

\begin{tabular}{|c|c|}
\hline \multicolumn{2}{|r|}{ External factors constraining and limiting digital transformation } \\
\hline State barriers & $\begin{array}{l}\text { 1. Economic uncertainty in the country, ruble volatility; } \\
\text { 2. Regulatory restrictions, lack of standards for the use of digital technologies; } \\
\text { 3. Lack of special measures of state support for the use of digital technologies } \\
\text { in enterprises }\end{array}$ \\
\hline $\begin{array}{l}\text { Competitive } \\
\text { barriers }\end{array}$ & $\begin{array}{l}\text { 1. The introduction of digital technologies requires costs on the part of } \\
\text { suppliers and consumers who adhere to the "traditional model"; } \\
\text { 2. Commitment of the end-user to familiar products (services); } \\
\text { 3. Lack of information about the successful experience or negative experience } \\
\text { of using digital technologies at other enterprises in the industry }\end{array}$ \\
\hline $\begin{array}{l}\text { Technological } \\
\text { barriers }\end{array}$ & $\begin{array}{l}\text { 1. Lack of digital solutions that take into account the specifics of the enterprise; } \\
\text { 2. Weak protection of digital technologies from criminal encroachments; } \\
\text { 3. Insufficient level of infrastructure development (low bandwidth of } \\
\text { communication channels, lack of access to mobile Internet, lack of data } \\
\text { processing centers, etc.); } \\
\text { 4. Lack of domestic analogs of software for a number of industry industries }\end{array}$ \\
\hline \multicolumn{2}{|r|}{ Internal constraints and constraints on digital transformation } \\
\hline Resource barriers & $\begin{array}{l}\text { 1. The high cost of projects for the use of digital technologies; } \\
\text { 2. Insufficient budgets that the company can allocate for projects using digital } \\
\text { technologies; } \\
\text { 3. High operating costs for systems using digital technologies; } \\
\text { 4. Outdated technical equipment of industrial enterprises, complicating the } \\
\text { introduction of new technologies }\end{array}$ \\
\hline Human factor & $\begin{array}{c}\text { 1. Lack of awareness of the benefits of digital technologies, misunderstanding } \\
\text { of the essence of digital transformation and its effects on the part of enterprise } \\
\text { management and decision-makers; } \\
\text { 2. Reluctance of employees to change their usual forms of work; } \\
\text { 3. Lack of qualifications among personnel using digital technologies; } \\
\text { 4. Lack of qualifications among personnel implementing and maintaining } \\
\text { digital technologies }\end{array}$ \\
\hline $\begin{array}{l}\text { Psychological } \\
\text { barriers }\end{array}$ & $\begin{array}{l}\text { 1. Lack of sufficient personal experience or negative experience of using digital } \\
\text { technologies in other enterprises; } \\
\text { 2. Possibility of successful implementation of the company's activities without } \\
\text { the use of digital technologies; } \\
\text { 3. Preservation and maintenance of information security of both infrastructure } \\
\text { and networks, and products in the process of its operation, preservation of } \\
\text { confidentiality }\end{array}$ \\
\hline $\begin{array}{l}\text { Organizational } \\
\text { barriers }\end{array}$ & $\begin{array}{l}\text { 1. The need to integrate technologies into the existing IT landscape and the } \\
\text { current infrastructure of the enterprise; } \\
\text { 2. Rigid organizational structure of enterprises, which makes it difficult to } \\
\text { change internal processes, regulations, workflow, approaches to receiving and } \\
\text { processing information. }\end{array}$ \\
\hline
\end{tabular}

The digital transformation is a unique tool of the digital revolution, with the timely and correct use of which domestic enterprises will have the opportunity to regain their lost leading positions in the new digital economy. For this, the digital transformation processes initiated at enterprises, first of all, must have a scientifically grounded methodological basis [8]. 
In Russian science, it would seem that such a new phenomenon as digital transformation has deep and relevant until now scientifically grounded developments in various fields of knowledge, rooted in the Soviet era. This creates additional competitive potential and opportunities for the development and implementation of a unique format for the digital transformation of economic systems in the Russian Federation.

\section{Conclusion}

The development of the digital economy provides an opportunity for communication, exchange of ideas, and experience. Online platforms allow you to combine efforts to create a business, invest, search for employees, partners, resources, and sales markets. Digital technologies can also play a key role in training employees, sharing knowledge, and implementing innovative ideas, including in the social sphere.

The development of digital technologies in the public sector of the economy is of great importance. Digital government and public services are increasingly seen as a cost-cutting tool while delivering more efficient services to citizens and businesses and as part of government efforts to preserve the environment. Digital government and innovative technologies can ensure the effective participation of public administration in shaping sustainable development. The digital government will allow government agencies to provide better services and be more open to the population [8]. It can help governments reduce environmental damage, promote efficient management of natural resources, and stimulate economic growth and the development of the public sector of the economy.

An analysis of the risks that hinder the creation of a full-fledged digital economy deserves separate consideration. Along with countries that are actively introducing and using new technologies, there are entire regions cut off from global information communications, not taking advantage of the advantages that allow the transition to a new type of functioning of the economic system. The differences lie not only in the level of technology, lack of investment resources, or low level of human capital development but also in the absence or poor functioning of institutions.

Several aspects can be distinguished among the prerequisites for the development of the digital economy in Russia [6].

First, the Russian education system has a high potential for training specialists in the digital economy. This is especially important, since in the digital economy, a person will focus mainly on the implementation of new opportunities and the systematic organization of interaction in the ecosystem of people and machines, and routine operations will be performed by machines.

Secondly, there are original organizational and technological solutions to create an effective infrastructure for the digital economy.

Thirdly, the integration and development of specific cases based on modern principles of the digital economy will create a synergistic effect and lead to the overall growth of the Russian economy.

The digital economy and digital transformation are among the priorities for improving the public administration system in our country today. The national program "Digital Economy of the Russian Federation" is valid until 2024, digital transformation is indicated as one of the national goals in the decree of the President of Russia "On the national development goals of the Russian Federation for the period up to 2030". The transition of the state to the digital economy requires not only the introduction of technologies, the development of a new concept of work, but also the training of personnel who will be able to use new methods and observe new principles.

Regional programs and projects in the field of the digital economy are being implemented in the constituent entities of the Russian Federation. Most of the regional projects are carried 
out in areas similar to those in which federal projects of the national program are being implemented. In connection with the adjustment of the passports of federal projects of the national program, it is necessary to make appropriate changes to regional projects, to approve new indicators and methods for their calculation [9].

During the implementation of the national program, conditions have been formed for a large-scale systemic digital transformation of industries and sectors of the economy. During the pandemic of the new coronavirus infection, digitalization processes intensified, support for the development of digital technologies, the digital transformation of companies, government, education, medicine increased, and the social function of digital technologies and services increased.

At the same time, the measures taken to curb the spread of the new coronavirus infection revealed the unresolved problem of digital inequality, the need to ensure universal access to the information and telecommunications network "Internet" and connect socially significant objects to it [7].

The task of developing and supporting domestic software, including messengers and corporate platforms for training and work, has become urgent.

In addition, in the context of the demand for online services, the requirements for the level of protection of information contained in state information systems, including personal data, have increased.

\section{References}

1. I.L. Avdeeva, Analysis of the prospects for the development of the digital economy in Russia and abroad. Digital Economy and Industry 4.0: Problems and Prospects Proceedings of the Scientific and Practical Conference with International Participation, 19 (2019)

2. V.G. Varnavsky, Drukerovsky bulletin, 73 (2020)

3. P.V. Gulyaev, Regional economy: theory and practice, 10 (2019)

4. A.M. Druzhinin, Strategy for Knowledge Sharing in the Digital Economy, Age of Quality, 125 (2020)

5. E.V. Popov, K.A. Semyachkov Features of managing the development of the digital economy, Management in Russia and Abroad, 54 (2020)

6. I. Barron, R. Curnow, The Future with Microelectronics: Forecasting the Effects of Information Technology, 89 (2019)

7. F. Cruz-Jesus, T. Oliveira, F. Bacao, Z. Irani, Assessing the pattern between economic and digital development of countries, 56 (2020)

8. F. Dakhaeva and A. Amirova, Socially-oriented economy as part of the macroeconomic development system, 5 (2020)

9. F. Dakhaeva, Large Cities in the Process of New Industrialization, 6 (2020)

10. K. Murtazova and M. Abdulkadirova, The Consumer Market in the New Economy, 2 (2021) 